\title{
Warnings and packaging
}

\section{Richard O'Connor}

The current issue of Tobacco Control highlights recent developments in research related to tobacco packaging, including issues as diverse as health warnings, plain packaging, messaging and novel products. Since the implementation of the first pictorial cigarette warnings by Canada nearly two decades ago, to the first implementation of plain packaging (PP) by Australia in 2012, the literature on this field has blossomed and diversified. The ability of health warnings to remain relevant and continue to command attention is an important question in public health education. Woelbert and d'Hombres ${ }^{1}$ conducted a large experimental study in 10 European countries that had implemented differing warning styles. They find that graphic and text combined have a maximum effect in reducing intentions to smoke, but that this was attenuated in countries that had already implemented this warning style. Novel pictures reversed the wearout effect, providing evidence to support rotating warning content over time.

Green $^{2}$ and colleague address the issue of changing warnings from a different perspective, looking at the introduction of new warning content and the removal of other content as new, larger warnings were implemented in Canada. Adding and removing content from warnings generally affects smoker knowledge-removing carbon monoxide (CO) and impotence warnings led to decreased awareness that these were associated with smoking while adding blindness and bladder cancer warnings increased awareness, although adding an addiction warning had a little effect. Novelty appears to be important to consider when adding content, though it is also important to consider the educational implications of removing warning content entirely.

Sutton $^{3}$ and colleagues address the question of what features of pictorial warnings have the greatest impact by coding existing warnings from the UK, Australia, New Zealand and Canada and gathering feedback from US smokers. Diseased body parts, testimonials and warnings with multiple blocks of text were

Department of Health Behavior, Roswell Park Cancer Institute, Buffalo, New York, USA

Correspondence to Richard O'Connor, Department of Health Behavior, Roswell Park Cancer Institute, Buffalo, NY 14226, USA; richard.oconnor@roswellpark.org viewed as most effective at discouraging smoking, and effectiveness, intentions to avoid smoking and warning avoidance were mediated by the level of negative emotion elicited. The shock of graphic warnings has given way in several markets to even starker packaging-a lack of brand imagery paired with large warnings is now implemented or adopted in 14 countries. White et $a l^{4}$ review the long-term effects of plain packaging in the first country to move forward, Australia. They show that smoking prevalence has continued to drop among youth, with coincident drops in appeal of smoking and increases in uncertainty that there are differences across cigarette brands. They also found no change in the level of noticing the health warnings, suggesting sustained effectiveness over time.

El-Khoury $^{5}$ and colleagues present data from adolescents in France, which implemented plain packs more recently, surveying cross sectionally before and after implementation. They report that PP appears to increase adolescent risk perceptions of smoking and reduce initiation and brand attachment, providing initial evidence that plain packs change adolescent norms around smoking. There was also suggestive, though non-significant, evidence for inducing quitting in adolescents.

While, historically, most research on health warnings has focused on cigarettes, there is a growing need for evidence to support health warning implementation and content on non-cigarette tobacco products. King et $a l^{6}$ examine the data from the first two waves of the Population Assessment of Tobacco and Health (PATH) study in the USA for self-reported exposure to manufacturer-implemented warnings on waterpipe tobacco products, prior to the August 2018 requirement to place a nicotine warning on waterpipe tobacco. About one-third of users reported seeing some type of warning, and this was associated with having regular brand and purchasing for self. Seeing a warning was associated with increased risk perception, but not future waterpipe use. Maziak ${ }^{7}$ and colleagues, in a within-subjects experiment, showed that smoking topography was less intense, $\mathrm{CO}$ intake and subjective ratings were lower, and risk perceptions higher during smoking with a cancer warning placed directly on the waterpipe, compared with a no-warning condition.

Brewer $^{8}$ and colleagues (Editor's choice) conducted a randomised trial to examine whether warnings on Electronic Nicotine Delivery Systems (ENDS) about nicotine and addiction, which do not appear on cigarettes, could induce smoking. They showed that the warnings discouraged vaping, but found no evidence that ENDS warnings encouraged smoking. Further, they showed that increased intentions to quit vaping were associated with exposure to the warning. Sontag ${ }^{9}$ and colleagues explored potential pictorial additions to the current Food and Drug Administration (FDA) nicotine warnings on e-cigarettes in a web survey. Pictorial ranked higher than text only, and a yellow caution triangle was ranked as most effective.

In markets where brand imagery is still permitted on packaging, a number of issues emerge that are of policy significance. Lee ${ }^{10}$ and colleagues show in an experiment that including more Marlboro branding on iQOS packaging was associated with increased perceived quality and safety and appeal, but no substantial effect on affect or intentions to use. Gratele $^{11}$ showed that the agreement reached between FDA and RJR regarding American Spirit's use of additive free may not have gone far enough to correct public misperceptions. They show that also removing the term 'natural' from the brand name and removing the description of the product as containing only tobacco and water would be more effective at correcting misperceptions of safety and would also reduce intentions to use. Borland $^{12}$ and colleagues show that after the implementation of a menthol ban in Ontario, there was an increase in blue colours on packaging and greater use of the term smooth. Finally, Panigrahi ${ }^{13}$ shows that the packaging of tobacco products sold in a very poor area of India is not in compliance with legal requirements, meaning the poorest tobacco users continue to be misled.

We can draw a few lessons from this excellent collection of papers. First, pictorial health warnings are effective in reducing smoking intentions, particularly when they activate negative emotions and are paired with plain or standardised packaging. There also appear to be substantial commonalities across different nicotine delivery systems-this should provide solace that scientists need not reinvent the evidentiary wheel for each novel product the tobacco industry develops. However, novel products may raise practical issues with regard to packaging and warning 
exposure that were immaterial for cigarettes. In the case of waterpipe, ENDS and iQOS, the unit of purchase that carries the warning may not be seen by the consumer or could be discarded shortly after purchase, reducing its potential effect. For example, an ENDS user may see a warning on the box or bottle of their liquid, yet they typically do not carry this around like a pack of cigarettes, reducing opportunities for the repeated exposures that help reinforce warning messages. The interesting initial findings for the effectiveness of cancer warnings placed directly on waterpipes for reducing consumption and increasing risk perceptions raise the prospect that this could be applied to other products. Future research should look at the positive and negative consequences of placing health warnings directly on ENDS devices or tobacco heating devices such as iQOS. Finally, concerns about untoward effects of ENDS warnings potentially encouraging smoking appear to be overstated. All in all, this collection of papers illustrates the maturity of the field and potentially exciting directions for the future.

Funding The authors have not declared a specific grant for this research from any funding agency in the public, commercial or not-for-profit sectors.

Competing interests None declared.
Patient consent for publication Not required.

Provenance and peer review Not commissioned; externally peer reviewed.

(C) Author(s) (or their employer(s)) 2019. No commercial re-use. See rights and permissions. Published by BMJ.

\section{Check for updates}

To cite O'Connor R. Tob Control 2019;28:e1-e2.

Tob Control 2019;28:e1-e2.

doi:10.1136/tobaccocontrol-2019-055192

\section{REFERENCES}

1. Woelbert $E$, d'Hombres B. Pictorial health warnings and wear-out effects: evidence from a web experiment in 10 European countries. Tob Control 2019. doi:10.1136/tobaccocontrol-2018-054402. [Epub ahead of print: 04 Jan 2019].

2 Green AC, Driezen P, Noar SM, et al. Impact of adding and removing warning label messages from cigarette packages on adult smokers' awareness about the health harms of smoking: findings from the ITC Canada Survey. Tob Control 2019:tobaccocontrol-2018-054885.

3 Sutton JA, Yang S, Cappella JN. Perceived effectiveness of objective features of pictorial warning messages. Tob Control 2018:tobaccocontrol-2018-054488.

4 White V, Williams T, Faulkner A, et al. Do larger graphic health warnings on standardised cigarette packs increase adolescents' cognitive processing of consumer health information and beliefs about smoking-related harms? Tob Control 2015;24(Suppl 2):ii50-7.

5 El-Khoury Lesueur F, Bolze C, Gomajee R, et al. Plain tobacco packaging, increased graphic health warnings and adolescents' perceptions and initiation of smoking: DePICT, a French nationwide study. Tob Control 2018:tobaccocontrol-2018-054573.
6 King JL, Reboussin BA, Cornacchione Ross J, et al. Waterpipe tobacco package warning exposure's impact on risk perceptions and use among young adults in the USA: a longitudinal analysis of the population assessment of tobacco and health study. Tob Control 2018:tobaccocontrol-2018-054562.

7 Maziak W, Ben Taleb Z, Ebrahimi Kalan M, et al. Pictorial health warning labels on the waterpipe device are effective in reducing smoking satisfaction, puffing behaviour and exposure to $\mathrm{CO}$ : first evidence from a crossover clinical laboratory study. Tob Control 2019:tobaccocontrol-2018-054682.

8 Brewer NT, Jeong M, Hall MG, et al. Impact of e-cigarette health warnings on motivation to vape and smoke. Tob Control 2019:tobaccocontrol-2018-054878.

9 Sontag J, Manderski MTB, Hammond D, et al. Us young adults' perceived effectiveness of draft pictorial e-cigarette warning labels. Tob Control 2019. doi:10.1136/tobaccocontrol-2018-054802. [Epub ahead of print: 05 Jun 2019].

10 Lee JGL, Blanchflower TM, O'Brien KF. Evolving IQOS packaging designs change perceptions of product appeal, uniqueness, quality and safety: a randomised experiment, 2018, USA. tob contril 2018.10.1136/ tobaccocontrol-2018-054910

11. Gratale SK, Maloney EK, Cappella JN. Regulating language, not inference: an examination of the potential effectiveness of natural American spirit advertising restrictions. Tob Control:tobaccocontrol-2018-054707.

12. Borland T, D'Souza SA, O'Connor S, et al. Is blue the new green? Repackaging menthol cigarettes in response to a flavour ban in Ontario, Canada. Tob Control 2018:tobaccocontrol-2018-054454.

13. Panigrahi A, Sharma D. Compliance with packaging and labelling rules for tobacco products marketed in slum areas of Bhubaneswar, India. Tob Control 2018:tobaccocontrol-2018-054665. 